\title{
The Coherence Between Epistemologies and SSI Teaching
}

\section{A Multiple-Case Study with Three Science Teachers}

\author{
Arzu Sonmez Eryasar ${ }^{1} \cdot$ Ahmet Kilinc $^{2}$ \\ Accepted: 28 January 2021 / Published online: 13 April 2021 \\ (C) The Author(s), under exclusive licence to Springer Nature B.V. 2021
}

\begin{abstract}
The purpose of the present study was to understand the nature of the link between science teachers' epistemologies and their socioscientific issue (SSI) teaching discourse. It is important to consider this link due to the limitations of science teachers in shifting from monologic to more dialogic orientations in their teaching, despite SSI-based science education reforms in many countries. Teachers' epistemologies are likely to contribute to the difficulties experienced in this shift. We selected three science teachers using purposive sampling procedures. Using classroom observations and follow-up constructivism-oriented interviews, we selected one non-constructivist, one moderately constructivist, and one constructivist science teacher. We then examined these teachers' (knowledge-based and science-based) epistemologies by two semi-structured interviews. The teachers taught one SSI topic and then we conducted classroom observations. Benefiting from highly used classifications, we classified teachers' epistemologies and discourses in the transcripts. The results showed that there were some coherences and incoherences between science teachers' epistemologies and their SSI teaching.
\end{abstract}

\section{Introduction}

\subsection{Socio-Scientific Issues (SSI) in Science Education}

Issues such as GMO foods, nuclear power plants, and artificial intelligence are socioscientific issues (SSIs). These are the issues in which science, technology, and society are engaged and differences of opinion exist among scientists (Ratcliffe \& Grace, 2003). They have been put on the agenda especially in the past thirty years, and they have been included in science education programs for three main reasons (Kilinc et al., 2017a): (1) Nowadays, science has shifted from normal science (Kuhn, 1962) to post-normal science

Ahmet Kilinc

akilinc@uludag.edu.tr

Arzu Sonmez Eryasar

arzu.sonmez.eryasar@igdir.edu.tr

$1 \quad$ Igdır University, Igdır, Turkey

2 Bursa Uludag University, Bursa, Turkey 
(Ravetz, 2012). Normal science, which examines the relationships between the variables and the mechanisms behind these relationships, has been replaced by post-normal science, which includes risk calculations and uncertainties and contains technology and engineering elements and in which society is also an important stakeholder. Such a transformation required a similar transformation in science literacy, which resulted in the inclusion of SSI in science programs. (2) In examples such as Fukushima, swine flu, and coronavirus, governments expect the public to perform fair assessment of evidence. In such examples, it was observed that the public acted on the basis of their intuitions and perceptions of risk instead of rational and evidence-based reasoning, which resulted in the termination of most of the scientific and technological investments made by governments (Kilinc et al., 2017a). Therefore, governments consider that SSI-based science education will be influential (European Union, 2012). (3) Science educators in the past two decades showed that SSI-based science education has produced more effective results in conceptual understandings, epistemological beliefs, argumentation skills, and moral reasoning compared to other education models (Zeidler \& Kahn, 2014). These positive results have also led to the expansion of the SSI-based science education.

For these three main reasons, SSI has been included in science curriculum in Turkey, as in many countries. In the updates made in 2013, 2017, and 2019, one of the main objectives of Turkish science education, for example, was shown as making informed decisions on SSI (Milli Eğitim Bakanlığı [Ministry of National Education], 2013, 2017, 2019).

\subsection{SSI Teaching}

SSI, which has been integrated into science education, has a different epistemic nature compared to science topics based on normal science. Scientific knowledge produced on these topics includes uncertainties and relativities (Zeidler \& Nichols, 2009). In addition, there is interdisciplinary knowledge produced by many sciences and engineering fields (Kilinc et al., 2017a). Another situation is that there is a process in which many social actors, such as politicians, society, and the media, are also involved in the process of producing knowledge, instead of a process in which one scientist produces the knowledge and the other two confirm it as in normal science (Gayford, 2002; Lazarowitz \& Bloch, 2005). Furthermore, there is a model based on dialogue, instead of inductive and deductive knowledge production processes on which normal science is based. Another situation is that chaos-oriented mathematics based on risk calculations and uncertainties has been adopted instead of deductive mathematics on which normal science is based (Ravetz, 2012).

The mentioned epistemic differences indicate that a model which is different from normal science topics is required in the teaching of SSI. Especially when uncertainties and limited evidence are considered, there is a need for transition from monologic teaching to a dialogic one. In the monologic models, teacher speaks and students listen or take notes whereas teachers and students act together, arguments are mutually competed, and the contradictions in the evidence are emphasized in the dialogic ones (Ratcliffe \& Grace, 2003). At this point, argumentation and ethics-based discussions are recommended in the teaching of SSI (Zeidler \& Nichols, 2009).

In SSI teaching, although experts suggest a dialogic teaching, it is observed that the great majority of science teachers prefer a monologic teaching (Barrue \& Albe, 2013). At this point, some teachers did not see any difference between SSI and normal science topics, some teachers preferred a superficial education that focused on the benefits and harms due to the existing moral dilemmas on these topics, and even some teachers did not integrate 
these topics into their courses due to some uncertainties (Kilinc et al., 2017a; Johnston et al., 2001; Lee et al., 2006).

\subsection{Relationships Between Teachers' Epistemologies and Their Teaching}

Epistemological beliefs of teachers are indicated as one of the reasons why they prefer a monologic teaching instead of a dialogic teaching (Hofer \& Pintrich, 2004; Johnston et al., 2001). Epistemological beliefs refer to individuals' beliefs about the process of knowing and the nature of knowledge (Hofer \& ve Pintrich, 1997, 2002; Schommer, 1990, 1994). They are shaped in four areas: (i) certainty of knowledge, (ii) simplicity of knowledge, (iii) justification of knowledge, and (iv) sources of knowledge (Hofer, 2002). The researchers observed that individuals with naive epistemological beliefs believed that the knowledge was certain, stable, simple, and stacked; made justifications by eliminating the deficiencies in data through intuitions and emotions; and considered authorities as the source of knowledge. On the other end, in individuals with sophisticated epistemological beliefs, it is believed that knowledge involves changeable, relative, complex, and multiple relationships; that the justifications supported by more valid and reliable evidence would be more appropriate than the others; and that the evaluations made by the individual himself/herself are effective as the source of knowledge (Hofer, 2002).

In addition, some researchers have demonstrated that epistemological beliefs are both general (domain-generality) and specific (domain-specificity) Buehl \& Alexander, 2001; Muis et al., 2006), which indicates that some individuals make a distinction between the general nature of knowledge and the nature of knowledge specific to branches/domains. For instance, someone who considers "knowledge" relative may also consider the "scientific knowledge" certain. Similarly, someone who points to authorities for the source of "knowledge" may also consider that authorities in "social sciences" could be misleading and that it would be appropriate for the individual himself/herself to be the source. On the other hand, there are also many individuals whose domain-general and domain-specific epistemologies are coherent (Muis et al., 2006). (For clarity, we used the term "knowledgebased epistemology" for the domain-general epistemology and "science-based epistemology" for the domain-specific scientific epistemology in the following sections.)

It is known that there are relationships between teachers' (knowledge-based and/or science-based) epistemological beliefs and their teaching. Kilinc et al. (2017a), for example, defined teachers' epistemological beliefs as one of the three main teacher belief groups. According to this model, teachers consult their epistemologies as a heuristic in their daily teaching and their decisions. For instance, in the study conducted by Aky1ldiz (2014) with 1581 high school teachers, there was a positive relationship between knowledge-based epistemological beliefs and constructivist teaching. Aky1ldı showed that teachers with traditional pedagogical approach had naive knowledge-based epistemological beliefs. Similarly, in the study conducted with 49 pre-service science teachers, Kaplan and Akgul (2009) showed that there was a coherence between knowledge-based epistemological beliefs of pre-service teachers and their understanding of teaching and learning. In the studies conducted by Lederman (1992) and Appleton and Asoko (1996), it was observed that there was a coherence between the teaching and learning of science and science-based epistemological beliefs. At this point, teachers with more relative and dynamic scientific epistemologies preferred a more interrogative and constructivist science education. In a similar study, Tsai (2002) examined the relationships between science-based epistemological beliefs and the science learning and teaching approaches in 37 Taiwanese science teachers. 
The results showed that scientific epistemologies and the learning and teaching approaches were coherent in the half of the participants. While those with a more relative perception of science adopted a constructivist science learning/teaching, those with a more absolutist perception of science adopted a more traditional learning/teaching. In another subsequent study, Tsai (2007) showed that teachers with more positivist and absolutist science-based epistemologies attached more importance to students' test scores, performed teacher-centered teaching, and preferred an education focused on solving test questions by memorizing. On the other hand, teachers with more relative and constructivist science-based beliefs adopted an education which was based on questioning, dialogue between students, and the applications of science concepts.

There are also studies indicating that there is no full coherence between teachers' epistemologies and their teaching. For instance, in their study conducted with 2284 th-grade pre-service science teachers, Cheng et al. (2009) stated that there was no automatic relationship between pre-service teachers' knowledge-based epistemological beliefs and their teaching approaches. At this point, while pre-service teachers with more sophisticated epistemological beliefs were expected to adopt more constructivist teaching approaches, it was observed that some pre-service teachers preferred non-constructivist methods due to some realities such as the pressure to complete the curriculum. Similarly, in the study conducted by Manu (2014) with 50 teachers and 81 pre-service teachers, there were some exceptions although it was shown that knowledge-based epistemological beliefs and classroom practices were correlated. For instance, it was found that there was no relationship between constructivist teachers' teaching practices and knowledge-based epistemological beliefs, and this relationship only manifested itself in behaviorist teachers. With regard to this situation, constructivist teachers stated that they could not reflect their epistemologies on their teaching due to reasons such as workload, test solving, and realization of general education standards.

\subsection{Science Teachers' Epistemologies and Teaching of SSI}

When SSI teaching was specifically examined, Kilinc and Baltaci (2014) investigated the relationships between knowledge-based epistemologies and SSI (GM Foods) teaching efficacy with a sample including 382 pre-service science teachers. The results showed that the dimensions of epistemology such as "simplicity of knowledge" and "certainty of knowledge" negatively predicted SSI teaching efficacy dimensions of "argumentation" and "teaching nature of science." In addition, "omniscient authority," one another epistemology dimension, negatively predicted SSI teaching efficacy dimension of "magament of discussions." These results may mean that those with absolutist epistemologies do not find themselves efficient in teaching SSI having an incoherent epistemology with theirs. In one another study, Ozturk and Yilmaz-Tuzun (2017) investigated the relationships between pre-service science teachers' knowledge-based epistemological beliefs and their informal reasoning about nuclear power usage. They argued that pre-service teachers made their decisions on this issue either by using the value-oriented (for example, potential harm to the environment) decision-making or using evidence-based reasoning. In addition, there was no significant difference between these two decision-making groups in terms of the epistemologies, meaning that those with more sophisticated epistemologies do not necessarily make evidence-based decision-making. In addition, the certainty of knowledge, one of the knowledge-based epistemology dimensions, was negatively correlated with counterargument construction and total argument construction about SSI. In another study, 
Kilinc et al. (2017a) attempted to improve the (knowledge-based and science-based) epistemologies of a pre-service science teacher through an argumentation-based education and pursue the impacts of this education during the periods of teaching practicum (internship) and induction. Even if they observed a development in her (knowledge-based and science-based) epistemologies from absolutist position through relativistic one thanks to the education, they noticed that she experienced a pseudo-change during the education because she immediately turned back to absolutist notion during the follow-up periods of internship and induction. She, for example, mostly preferred a monologic teaching in her SSI-based teaching practicum and actual teaching experiences, and with regard to the reason for it, she indicated that it was difficult to control students during discussions and that there were other priorities such as completing the curriculum and discipline problems. In another study, Kilinc et al. (2017b) conducted a study on the reasons why pre-service science teachers preferred monologic and dialogic teaching in the teaching one of SSIs (GMO foods). This study showed that pre-service teachers who had naïve (knowledge-based and science-based) epistemologies, such as grounding on teacher authority and considering science independent of values, and values such as "protecting children from harmful foods" preferred a monologic SSI teaching. On the other hand, although pre-service science teachers who preferred a dialogic SSI teaching had sophisticated knowledge-based epistemologies such as student-centered decision-making, leaving the teacher in a guiding position and democratic education, they also revealed values such as "protecting children from harmful foods" with naive (knowledge-based and science-based) epistemologies such as reaching scientific facts by discussing and correcting students' ideas.

These results may mean that the incoherence issue becomes more complex in SSI teaching contexts than science teaching contexts due to two reasons. First, it seems that some (pre-service) science teachers prefer dialogic teaching despite their naïve epistemologies even if these results are based on self-reports (Kilinc et al., 2017b). Second, some science teachers with sophisticated epistemologies do not apply these epistemologies to their reasoning (Ozturk \& Yilmaz-Tuzun, 2017) and teaching (Kilinc et al., 2017b) and prefer monologic SSI teaching because of their personal values arising from the nature of SSI. In addition, the infrastructural reasons such as completing curriculum on time and discipline problems were stressed for selecting monologic SSI teaching by some (pre-service) science teachers with sophisticated epistemologies, as those in science teaching contexts.

\section{Objectives of the Study}

SSI has become indispensable for science literacy in the last thirty-year period during which science has shifted from normal science to post-normal science. These issues have been included in the curricula with the efforts of both governments and science educators. When the epistemic nature of these issues was examined, it was observed that they had differences compared to normal science topics taught in science courses, and especially, they were based on an epistemology that made dialogic teaching essential. However, when the available studies were examined, it was observed that the vast majority of the science teachers preferred monologic teaching. With regard to the reason for it, various researchers stated that science teachers' epistemologies could be an important factor because there is strong evidence indicating that teachers' (knowledge-based and science-based) epistemologies were coherent with their teaching. In this evidence, it was observed that teachers with naive epistemologies preferred a monologic teaching while teachers with sophisticated 
epistemologies preferred a dialogic teaching. However, this evidence contradicts with some opposite evidence. Some studies show that there is no full coherence between epistemologies and teaching and that especially teachers with sophisticated epistemologies do not reflect these epistemologies on their teaching due to various barriers. This confusion is particularly valid for the SSI teaching literature. At this point, the purpose of this study was to reveal the nature of coherence between three science teachers' epistemologies and their SSI teaching discourses in order to eliminate these confusions, though partially, and to better understand the relationships between SSI teaching and epistemologies. Such a study is considered to have a relative importance in a period during which SSI has been included in science curriculum and most of the teachers have preferred monologic teaching in an incoherent manner with this reform. Indeed, the data obtained can offer practical suggestions to improve the belief systems that will provide the transition from monologic teaching to dialogic teaching in the teaching of SSI. Within the scope of this purpose and significance, responses to the following research questions were sought:

Research Question 1. What is the nature of knowledge-based and science-based epistemologies of the selected three science teachers?

Research Question 2. What is the nature of SSI teaching of the selected three science teachers?

Research Question 3. What is the nature of coherence between the epistemologies of the selected three science teachers and their SSI teaching?

\section{Method}

Multiple-case study was employed by using a naturalistic perspective (Lincoln \& ve Guba, 1985). We used this perspective because we were aware of the fact that our personal beliefs influenced the analysis procedures and we aimed to investigate the structures and phenomenons within natural settings. The selection of cases, data collection tools, data collection process, data analysis, and validity and reliability processes are explained in the following section.

\subsection{Selection of Cases}

"Purposive sampling," which is frequently used in case studies, was used to determine the participants. It was aimed to reach three science teachers representing one of three coherence types between epistemological beliefs and (monologic or dialogic) SSI teaching. At this point, the courses of eight science teachers were followed, and their beliefs about "constructivist" teaching were obtained. Considering that both epistemic beliefs and SSI teaching, which are the focus points of this study, were directly associated with constructivist teaching (Hashweh, 1996; Hofer, 2004), it was thought that uncovering science teachers' beliefs and practices of "constructivism" would be appropriate for sample selection. Many previous studies (such as Tsai, 2002, 2007) consistently showed that science teachers' epistemologies and teaching orientations are nested within their constructivist profiles (Bryan, 2012). At this point, constructivist profile represents the teaching where the teachers are facilitators of students' conceptual development by producing learning environments in which students' conceptions are discussed collaboratively, authentic conceptual change opportunities are created and students' knowledge construction process is evaluated. On 
the other hand, non-constructivist profile represents the teaching where the teachers repeat the curricular knowledge with the expectation of same repeat from the students without connecting it with students' existing conceptions and students' repeat performances are evaluated at the end of teaching process (e.g., Tsai, 2000). Science teachers with constructivist profiles usually possess sophisticated epistemologies and exhibit dialogic practices, whereas those with non-constructivist profiles usually have naïve epistemologies and produce monologic practices (e.g., Tsai, 2007). In this way, we aimed to select "one nonconstructivist" (for investigating the possible coherence between naïve epistemologies and monologic SSI teaching), "one moderately constructivist" (for investigating the possible coherence between moderate epistemologies and moderate SSI teaching), and "one constructivist" (for investigating the possible coherence between sophisticated epistemologies and dialogic SSI teaching) science teachers (please see Table 1). In addition, these easy-touse designations represent teachers' teaching approaches rather than their identities, ideologies, etc.

First, we reached out to two middle schools where the first author studied. From her experience, we considered that we could reach all of the constructivist profiles there. After several informal interviews about volunteer participation and purposes of the present research, we decided to include four science teachers in one of the schools and three science teachers in the other. In addition, apart from convenience reasons, we particularly focused on these middle schools because our aim was to find the cases within the schools that were located in a region where the people with mid-level socioeconomic profile have been living and that were mid-level ones in terms of students' achievement scores in the national

Table 1 Constructivism profiles of the selected teachers

\begin{tabular}{|c|c|}
\hline Science teacher & Constructivism profile \\
\hline Non-constructivist & $\begin{array}{l}\text { The teacher mostly used traditional methods. She was in the center of teaching } \\
\text { (i.e., speaking, writing on the board, asking, directing, etc.). She stated that } \\
\text { teacher-centered teaching was the most accurate method. The materials in } \\
\text { the courses usually consisted of course books and what was written on the } \\
\text { blackboard. She rarely asked questions and her questions were only aimed at } \\
\text { finding out whether students were listening. Furthermore, she believed that } \\
\text { it was appropriate to perform assessment and evaluation activities after the } \\
\text { teaching process and mostly with test-oriented closed-ended questions }\end{array}$ \\
\hline
\end{tabular}

Moderately constructivist The teacher considered the constructivist approach useful compared to the traditional methods; however, she mostly used traditional methods in the classroom due to the obstacles that were stated by her to be caused by the education system. She included students in course with short-answer questions. Large class discussion was occasionally established; however, clear relationships were not established between students' responses. The discussions took place with the corrections and short feedbacks provided by her and teaching was performed mostly with teacher-centered discourses

Constructivist

The teacher considered the constructivist approach useful and effectively reflected it in the classroom. He usually divided the class into groups and preferred students to be included in the course through collaborative learning. In classroom discussions, he established relationships between students' responses and deepened students' responses with inspiring feedback for the next question. He asked deep questions for students to question the current situation instead of short-answer questions and made students apply the science concepts to daily life. Furthermore, he stated that he performed a process-oriented assessment and evaluation 
high school entrance examinations. We considered that such selection may efficiently represent Turkish context because most of the schools exist in this group. The courses of these seven science teachers (five females and two males) were observed for a total of 16 weeks, including two course hours each week. All of the observations were performed in the classrooms of fifth-grade students. The observation form developed by Ross et al. (2004) was used during the observations. According to this form, the first author collected information about the teacher's behaviors and teaching processes, and question-answer-feedback relationships as well as physical elements such as the materials used in the classroom and the general structure of the classroom. Three-step interviews were also conducted with teachers on constructivist teaching (interview forms are presented as Supplementary Material). During the interviews, personal information (demographic characteristics) was obtained in the first step, teachers' motivational beliefs (career selection motivators, perceptions about teaching profession, and metaphors about teaching) and beliefs about science teaching (teaching efficacy, perceptions about effective science teaching, the factors affecting science achievement, science teaching goals, and motivational attributions) were questioned in the second step, and the questions about constructivist teaching (teaching materials, decision-making about what to teach, perceptions about collaborative learning, assessment and evaluation methods, uncovering prior conceptions, constructivist philosophy, studentcentered teaching, and inquiry-based activities) were asked in the final step.

The data were analyzed after each interview and observation, teachers' general profiles for constructivist education were created, and by means of these profiles, it was decided to continue the study with the teachers who were considered to be at a different level. However, at this point, the analyses revealed that the purpose of obtaining three coherence situations and working with typical cases was not yet achieved. One of the seven teachers (who is a female) studied was "non-constructivist" and the other six (four females and two males) were "moderately constructivist." We randomly selected one of the moderately constructivist teachers (who is a female) because there were no salient differences in their teaching practices. At this point, it was decided to increase the number of participants studied in order to reach the "constructivist" teacher. At this stage, a science teacher (who is a male) who had previously participated in a long-term in-service training project on constructivist teaching was included in the sample. This teacher has been working in one another middle school with a similar profile in terms of socio-economy and achievement. With the classroom observations and constructivist teaching-oriented interviews, it was concluded that he was the "constructivist" teacher who was looked for the study. So, the study was continued with three teachers from a total of eight teachers by sticking to the principles of data triangulation. While one of these teachers was "non-constructivist," another one was "moderately constructivist" and the other one was "constructivist." The profiles created for the teachers who were selected through observations and interviews are presented in Table 1.

\subsection{Data Collection Tools and Data Collection Process}

A two-step data collection process was used in order to reveal the epistemologies and SSI teaching discourses of selected three science teachers. While epistemologies were revealed through semi-structured interviews, classroom observations were performed for uncovering SSI teaching discourse. In the interviews, the participant teachers were asked questions about their knowledge-based and science-based epistemological beliefs. In the observation stage, it was waited until it was time for one SSI topic in the curriculum, and when it was 
time for the topic, the selected teachers were asked to record a two-hour course with a camera during their SSI teaching. Using this camera recording, teachers' SSI teaching discourse was revealed with an Observation Evaluation Form. The data collection tools used in the data collection process are introduced in the following section and incorporated into text as Supplementary Material:

1. "The Epistemic Belief Scenario" developed by Kuhn et al. (2008) was used to reveal knowledge-based epistemologies. This scenario included two different approaches related to the extinction of the dinosaurs. It was translated into Turkish by the back translation method. The scenario was shown to the participants, and they were asked to answer the questions at the end of the scenario by giving sufficient time to read the scenario. It was questioned which of the two different approaches, in which the same case was interpreted, participants were mostly sure of. In addition, one more semistructured interview was conducted using a form called "Characteristics and Construction of Knowledge" in order to support this scenario-based interview and to obtain richer knowledge about knowledge-based epistemologies. In this interview, the items in the previously developed and frequently used scales (Hofer, 2004; Hofer \& ve Pintrich, 2002) were used to develop the questions. The form includes questions about the description of knowledge, knowledge-belief relationships, the structure of knowledge, sources of knowledge, and the accuracy of knowledge. These two interviews were conducted in different weeks, in an environment away from noise and by recording with a voice recorder.

2. "The Views of Nature of Science Questionnaire-Form C" developed by Lederman et al. (2002) was used to reveal science-based epistemologies. This interview form consisting of ten questions was back translated into Turkish by Eroğlu (2012) and the translated version of the form was used in the study. The themes such as the description of science, the role of experiments in science, differences between theory and law, creativity of scientists, tentativeness of scientific knowledge, and the effects of socio-cultural factors in science were examined through interview questions. The interview was conducted in an environment away from noise and by recording with a voice recorder.

3. The Dialogic Discourse Quality Observation Form developed by Reznitskaya (2012) and previously used to analyze SSI teaching discourse by Kilinc et al. (2017b) was used to reveal SSI teaching discourse. The participant teachers were asked to videotape a two-hour course selected by them in which they performed SSI teaching. At this point, teachers were given some technical information about where to put the camera in the classroom and how to use it. The teachers who completed the video records delivered the records to the authors.

\subsection{Data Analysis}

In qualitative research, there are two types of data analysis approaches, including inductive and deductive (Kodish \& Gittelsohn, 2011). In the analysis of the results of the interviews and observations conducted, comparisons were performed by considering the similarities and differences, and deductive coding was used. The epistemic profile categories developed by Kuhn (2001) were used while analyzing the knowledge-based epistemologies. Kuhn (2001) categorized individuals epistemically as "absolutist," "multiplist," and "evaluativist." While absolutist individuals seek clear and precise knowledge and quickly adopt a certain approach, multiplist individuals state that there may be 
different approaches and these differences are caused by different interpretations of people, and evaluativist individuals state that although there are different interpretations, some interpretations supported by clearer evidence are more valid than others. The transcripts of the interviews conducted with the "Epistemic Belief Scenario" and the "Characteristics and Construction of Knowledge" forms were read twice independently by the two authors, and the statements that were coherent with the profiles expressed by Kuhn (2001) were selected. After this election, the arguments that were initiated by the decided categorization and justified by the statements selected from two interview forms and that represented sometimes one or more than one profile were created for each participant. Furthermore, repeated discussions were held until a full consensus was reached when there were differences of opinion with regard to categorization between the two researchers. An example categorization process is shown in Table 2.

In addition, the categories developed by Songer and Linn (1991) were used to reveal science-based epistemologies. These categories were "static," "dynamic and static," and "dynamic." Individuals with a static profile have a more positivist belief and think that science can give clear and precise answers to all questions, scientific laws do not contain relative elements, and uncertainties will be eliminated in a short time through correct experiments, observations, and mathematical tools. On the other hand, individuals with a dynamic profile believe that there may be uncertainties and relative elements in scientific studies, and they think that science is a creative and social process and that stronger scientific arguments are supported by more and valid evidence. Dynamic and static individuals jointly share some themes from the two previous profiles. The transcripts of the interviews, which were conducted using the Views of Nature of Science Questionnaire-Form C, were extracted, and the procedures that were applied in the categorization process in knowledge-based epistemologies (please see Table 2) were also exactly applied in this process.

The Dialogic Inquiry Observation Form developed by Reznitskaya (2012) was used as a rubric in categorization of SSI teaching discourses. This rubric includes six themes including (1) Authority (whether the teacher has control over the discussion process), (2) Questions (discussion of titles and topics with deep or superficial questions), (3) Feedback (presence of inspiring feedback for the next step), (4) Meta-level reflection (whether relating students' answers), (5) Explanation (encouraging students to explain their ideas), and (6) Collaboration (whether ideas are co-constructed). In each theme, 1 and 2 points represent a monologic (where the teacher is dominant) discourse, 3 and 4 points represent a monologic-dialogic (where teachers and students are equally dominant) discourse, and 5 and 6 points represent a dialogic (where students are dominant) discourse. Firstly, a total of 80 min of records, consisting of two course hours, recorded by each participant teacher were transcribed. In the second step, the statements that represented the dialogue between the teacher and the students in transcripts were renamed as "questions," "answers," and "feedbacks." Because classroom discourse is expressed as a triadic dialogue (Cazden, 2001; Lemke, 1990), seven-minute sections with the most intense questions-answer-feedback patterns were selected for each record, and they were scored using the form developed by Reznitskaya (2012) (this duration was particularly selected because the most intense triadic dialogue took seven minutes for non-constructivist teacher and it was then decided to compare equal content of video material for each teacher). In this process, two authors performed the scoring independently from each other, and repeated discussions were held until a full consensus was reached between the researchers in case of any difference of opinion, as in the interviews. 


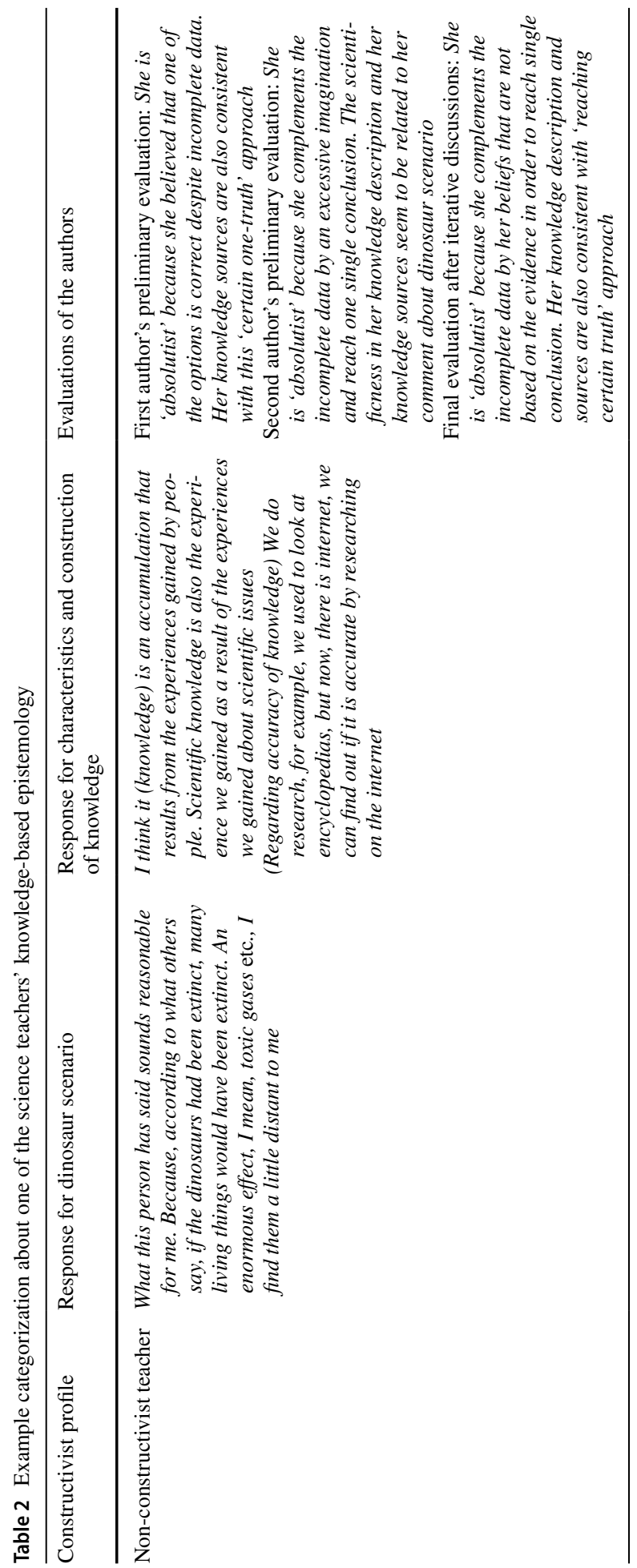


After determining the types of epistemologies and SSI teaching discourses for each teacher, we first investigated the coherence between epistemologies and teaching discourses within the cases. At this point, we particularly focused on which epistemologies match with which specific teaching activities. The main themes in the content of epistemologies such as certainty, simplicity, justification, and sources (Hofer \& Pintrich, 2004) also helped us seeing these matching situations. After uncovering the coherences within the cases, we applied a cross-case analysis in order to investigate the differences and similarities among the cases and asked "how" and "why" questions whenever we noticed such comparative situations.

\subsection{Validity and Reliability}

The processes proposed by Lincoln and ve Guba (1985) were used to ensure the validity and reliability of the knowledge produced in the study. First, a "long-term study" was planned to construct the credibility of the knowledge produced. The observations continued for about six months, and the study covered approximately one academic year in general terms. Interviews and observations were performed to ensure "data triangulation." Furthermore, data analyses were performed using "peer assessments."

"Negative case analysis" was performed as another case, the data obtained were subjected to "comparative analysis," and the cases that could create a contrast to the emerging categories were determined. In addition, "member check interview" was conducted at the end of the study with the teachers who participated in the study. The categorizations and profiles made in this interview were shared with teachers and their approval was sought. Furthermore, with this interview, the cases that could not be explained in the data analysis process were asked directly.

\section{Results and Interpretations}

\subsection{Epistemologies of Science Teachers}

As shown in Table 3, the knowledge-based epistemology of the non-constructivist teacher was categorized as "Mostly Absolutist," which was due to the fact that the teacher had several "evaluativist" statements. This teacher considered knowledge as concrete accumulation. While describing the knowledge, she stated that I think it is an accumulation that results from the experiences gained by people. Scientific knowledge is also the experience

Table 3 The coherence between the epistemologies of the selected teachers and their SSI teaching

\begin{tabular}{llll}
\hline Science teacher & $\begin{array}{l}\text { Knowledge-based } \\
\text { epistemological } \\
\text { beliefs }\end{array}$ & $\begin{array}{l}\text { Science-based } \\
\text { epistemological } \\
\text { beliefs }\end{array}$ & SSI teaching discourse \\
\hline Non-constructivist & Mostly absolutist & Static & $\begin{array}{l}1 \text { and } 2 \\
\text { Monologic }\end{array}$ \\
Moderately constructivist & Mostly evaluativist & Mostly dynamic & $\begin{array}{l}2 \text { and 3 } \\
\text { Mostly monologic }\end{array}$ \\
Constructivist & Evaluativist & Dynamic & $\begin{array}{l}5 \text { and 6 } \\
\text { Dialogic }\end{array}$ \\
\hline
\end{tabular}


we gained as a result of the experiences we gained about scientific issues. With regard to ensuring the accuracy of knowledge, she stated that We do research, for example, we used to look at encyclopaedias, but now, there is internet, we can find out if it is accurate by researching on the internet. These statements show that the teacher thought that she could somehow make the knowledge verified from different sources and believed that certainty could be achieved. When she was asked to evaluate two different approaches related to the extinction of the dinosaurs in the epistemic belief scenario, it was observed that she found the statements of one of the approaches sufficient, though partially, although there was insufficient evidence in the scenario. She stated that What this person has said sounds reasonable for me. Because, according to what others say, if the dinosaurs had been extinct, many living things would have been extinct. An enormous effect, I mean, toxic gases etc., I find them a little distant to me. Regarding science-based epistemologies of the same teacher, it was observed that she had "Static" epistemologies, as shown in Table 3. She stated that the only way to produce scientific knowledge was the experiment and that scientific laws were unchangeable facts. In addition, she thought that science was universal and not affected by socio-cultural norms. She stated that I think science is universal. If it has changed according to social and cultural values, then a great chaos will take place.

The knowledge-based epistemology of the moderately constructivist teacher was categorized as "mostly evaluativist" in Table 3. She used "multiplist" statements at some points although they were limited. In the question about the description of knowledge, she expressed knowledge as an opinion. She stated that when you say knowledge, actually, it is mostly opinion. I think it is something that you have developed about an issue, by observations, may be depending on your life experiences, that you say I think that it is so, it is actually knowledge, but opinions mainly determine it. In addition, she described knowledge not as independent parts, but as a structure that has complex relationships and consists of interconnected parts. With regard to the structure of knowledge, she stated that Now, when we consider the universe as a whole, it is not very reasonable that they are independent parts. It is absolutely necessary for a whole system to have small parts that work. Therefore, no matter how big the mass looks, for example, you might think a galaxy is a very big and independent thing, but you cannot go beyond the rules of the universe and work separately. So, there are certain rules functioning in the universe, there are rules and every piece is a small part of that universe system. In addition, she stated that she could rely on the knowledge coming from the authorities, though not exactly, and that scientists could not always be reliable in terms of objectivity.

Furthermore, for different approaches in the dinosaur scenario, she stated that both people in the scenario could not be sure and needed more evidence to be sure. In this regard, she stated that both of them cannot be sure and there is a need for more data. It is a very early stage to be sure for both views. Now, for example, in the first one, it is claimed that it leaves a lot of dust with the meteor hit and this dust prevents sunlight, so it is a cold and nonphotosynthetic environment. The other one assumes that the dinosaurs died due to cold climate and hunger for a similar reason, however, on the contrary, it was related to high temperature and toxic gases due to the extreme heat and greenhouse effect and the failure of photosynthesis. Absolutely neither can be sure, I think. There is a need for much more data. Regarding her science-based epistemologies, it was observed that she had "mostly dynamic" beliefs, as shown in Table 3, which was caused by the fact that she also had "static" beliefs at some points. She described science as the investigation of the being and stated that the evidence was very important and scientific knowledge had an ever-changing and developing structure. With regard to the changeability of scientific knowledge, she stated that now, we know what has been discovered, we speak as far as we 
know, but of course since we do not know the whole, it is inevitable for theories to change and even to change completely, something completely different may emerge. For example, while the atom is considered to be an indivisible particle, the whole world now knows that it is a divisible particle. In addition, she thought that science was affected by socio-cultural values. In this regard, she stated that ...it also includes beliefs, general view of societies, therefore, I do not think that there can be a very natural science. It cannot be very natural, I think that it is not very possible that there would be a situation that has not been affected by anything social.

The knowledge-based epistemologies of the constructivist teacher was categorized as "evaluativist" in Table 3. He stated that knowledge had a changeable structure, the most valid knowledge on the conditions of the day was described as scientific knowledge, and knowledge consisted of interconnected parts. He stated that for instance, when knowledge is mentioned, I mean, scientific knowledge, let me say its accuracy is based on the observations or experiments conducted. Indeed, it is not correct to utter accuracy or validity, only the 'knowledge with high validity in the current conditions' should come to mind. With regard to how knowledge should be verified, he stated that knowledge had no certainty and that knowledge might change according to existing conditions. In the scenario related to dinosaurs, he stated that he could not be sure about an approach and that there were uncertainties. He stressed that so, at this point, it is not possible to be further sure, but, I can say that there is natural selection with respect to the extinction of the dinosaurs. However, what caused this natural selection is still not clear from the examples we have given. Regarding his science-based epistemologies, it was observed that he had "dynamic" beliefs, as shown in Table 3. He described science as the interpretation of knowledge and indicated that experiment was not necessary in science and that studies could be conducted with different methods such as nature observations and modeling. In addition, he stated that scientific theories were open to change. In this regard, he stressed that "yes they (theories) change over time, for example, the atomic theories that you know have changed a lot over time...it is something related to current conditions, anyway... Since they change with the current conditions, we have to learn them under the conditions of that day, theories may change when the conditions of the day change over time."

\subsection{SSI Teaching Discourses of Science Teachers}

When the SSI teaching discourse of the non-constructivist teacher was examined, it was observed that she conducted a course related to "technology and radiation." Her course was progressed with a "monologic" discourse. A dialogue that was taken from the course and considered to largely represent the course is presented below:

Teacher: Television, mobile phone, what are all of them? Electrical appliances emit radiation to their surroundings, is there any other?

Student 7: There is vacuum cleaner

Teacher: Vacuum cleaner! Children, electrical appliances emit radiation to their surroundings. For example, television; It is an instrument that we use to have a good time, to be aware of the world and to follow the news, but when we stay in front of television for a long time, what do we do with the radiation that it emits, thought little? We are affected by it. Radiation is a factor that negatively affects the human health, do you know what kinds of negative effects can radiation have on our body?

Student 8: Genetic disorders 
Teacher: It causes genetic disorders, what else?

Student 7: Teacher, I will say something different, when we talk on the phone for too long, it hurts our ears.

Teacher: How does it primarily affect our ears? It damages our brain. Due to the radiation it emits, for instance, you should not place your mobile phone under your pillow or in a place near you while lying down at night. It is more inconvenient to have a mobile phone or a computer, especially in rooms with babies... Children, radiation causes various diseases in the human body. What is the most common disease today? Cancer. Cancer diseases are increasing day by day, this nuclear pollution is surely one of the factors that trigger this cancer disease. Then, pregnant women should stay away from these technological tools, because what about the baby's health during pregnancy, it may be negatively affected.

When the above dialogue was examined, the non-constructivist teacher shared some knowledge that was not appropriate to the epistemic nature of SSI and was not yet proven with sufficient evidence. She also expressed the opinion of "technology emits radiation and negatively affects the health" like certain knowledge. In addition, the course progressed with dialogues in which the teacher was dominant, and that the teacher asked the questions to herself and answered them by herself and rarely asked confirmatory and short-answer questions to students. Furthermore, deep questions in which different students' answers could be engaged were not asked and that no collaboration was established among students.

When the SSI teaching discourse of the moderately constructivist teacher was examined, she conducted a course on "nuclear energy." This course progressed with a "mostly monologic" discourse, although it moderately contained dialogic elements compared to the non-constructivist teacher. A dialogue that was taken from the course and considered to largely represent the course is presented below:

Teacher: Now, while thinking about it, finally say this, do we object to nuclear energy because of its hazards or shall we support it?

Multiple Shouts from the Classroom: Object to it.

Teacher: For what reason will we object to it? Why do we object to it? Why?

Student 1: Air pollution

Teacher: What are its other hazards? What else?

Student 4: Noise pollution

Teacher: More dangerous than that.

Student 6: Environmental pollution

Teacher: Give a name, let's say because of this reason.

Student 2: Undoubtedly, it has an additional harm by polluting the air, water and soil, we did not say it.

Student 9: It causes damage to people.

Teacher: So, for what it gives off to the environment, what does it emit it to the environment?

Student 10: Radiation.

Teacher: Because it gives off radiation. Yes. We have experienced the greatest danger of it very recently, have not we? Where and when was it? There was a huge amount of radiation leakage, there was a great danger. Where was it?

Student 10: Teacher, it took place in two cities in Japan.

Teacher: In other words, atomic bombs transmit radiation to the environment. Moreover, nuclear power plants that contain nuclear fuel that we use to generate electricity 
also contain radiation hazards. Well, What is the radiation hazard for people? What is radiation? It's a ray, isn't it? One of the invisible rays. What kinds of hazards it cause to the body?

Student 28: Handicapped births?

Although the moderately constructivist teacher started the above dialogue by suggesting two different alternatives, she had an expectation about the damages of nuclear power plants while constructing the question. Indeed, she developed many exchanges in the dialogue on damages and did not use the opportunities to produce counterarguments about its possible benefits. Although she had more question-answer relationships with the students compared to the non-constructivist teacher, her search for answer was mainly aimed at finding the expression having the definitional certainty in her mind. However, the fact that one of the students wanted to explain the answer by justifying it can be shown as a dialogic element. On the other hand, although it seemed that there were mutual exchanges, the teacher directed the discussion and the students were put into the background by trying to find what was in the teacher's mind. Furthermore, there were no cases where students worked together or related their ideas to each other.

When the SSI teaching discourse of the constructivist teacher was examined, he conducted a course on "nuclear energy." This course progressed with a "dialogic" discourse. A dialogue that was taken from the course and considered to largely represent the course is presented below:

Student 19: Yes, teacher, may I ask something? In addition to what you have said, when I came to the hospital, it was written on the X-ray that pregnant women and those with suspected pregnancy cannot enter. Is it radiation?

Multiple Voices from the Classroom: Radiation, it gives off radiation ...

Teacher: What does radiation mean?

Student 12: Damage, you know.

Teacher: Is it something harmful?

Student 21: It is a harmful type of light, for example, X-rays and ultraviolet rays can be examples of them.

Teacher: Yes?

Student 22: It may be something that is transferred to us from technological tools.

Teacher: Maybe, well. What else?

Student 5: Teacher, for example, the nuclear power plant exploded in Russia, it was released into the air, arrived the Black Sea by wind, fell on tea and hazelnut as rain in the Black Sea, so people had cancer because they ate them.

Teacher: Cancer occurs, yes. What else, have you heard anything else? For example, it is desired to build a nuclear power plant in Mersin, if you watched the news, people object to it, do we have to object? Or why should we build?

Student 2: Yes, it is necessary to object, because when it is demolished, Turkey may receive radiation.

Teacher: Is it possible to demolish it?

Student 3: There was an earthquake and it was demolished.

Student 2: It is better not to build it.

Teacher: Why it might be better if they do not build?

Student 4: Teacher, nuclear power plants ultimately cause environmental pollution, no matter what they do.

Teacher: OK, what do you think about nuclear power plants? Yes, a huge amount of energy is released in nuclear power plants, which is now on the agenda. Since there 
is a need for energy in our country, nuclear power plants are built so that most of the energy can be supplied by nuclear power plants. Considering the establishment of nuclear power plants, do you think is it necessary to build power plant? Or, if not, where should we get our alternative energies?

Student 19: Teacher, for example, let's say umm...nuclear power plant should not be built because the energy released when it explodes may lead to disabled births, wind turbins instead of it, Then...

Teacher: Wind power.

Student 19: Wind energy or hydroelectric power plants should be built, yes.

Student 12: Teacher, nuclear power plants should not be built because let's say it didn't explode, if a bomb or something is thrown it will explode again, let's say it didn't happen either, people will be damaged even in the smallest leakage.

Teacher: So, wouldn't this work without leaking?

Student 12: It depends.

Teacher: If we set it up, we say if there is no leakage, would it be possible?

Student 12: Still impossible.

Multiple Voices from the Classroom: Impossible.

Teacher: Why?

Student 12: Let's say you have built it in a country, but one of the country's enemy countries threw a bomb there and they will be damaged again.

When the SSI teaching discourse of the constructivist teacher was examined, he did not have a clear position on nuclear power plants and did not attempt to impose his own opinion as if it was exact knowledge or to push students towards that direction. While students focused on the damages of nuclear power plants, he asked them to think in a multiple way and deepen their reasons by building counterarguments. Furthermore, he also encourages them to refute his counterarguments. In addition, students generally directed the discussion, answered each other's questions, and related each other's answers. Furthermore, the teacher occasionally expressed the incoherencies or deficiencies in the statements of the students, as in the Socratic discussion. Moreover, he asked students to provide justifications by asking the question "why" too much and he wanted to create a multi-discussion environment by saying "what else?".

\subsection{Coherence Between the Epistemologies of Science Teachers and Their SSI Teaching}

When it is considered in general, it can be said that the epistemologies of the non-constructivist and the constructivist science teachers and their SSI teaching were coherent. However, unexpected coherence cases were observed in the moderately constructivist teacher, and these specific cases are interpreted in detail in the following section.

When the epistemologies and SSI teaching in the non-constructivist and constructivist teachers were considered together, we can argue that four main areas (i.e., certainty, simplicity, justification, and source) that constitute the content of epistemologies were reflected in their SSI teaching, in an expected manner. For instance, the non-constructivist teacher, who had a more absolutist and static position about certainty of (scientific) knowledge, shared the knowledge of that technologies emit radiation and that radiation is harmful, which was certain according to her with the class, and she attempted impose it to students in some way. On the other hand, when the constructivist teacher was considered from the same angle, he found (scientific) knowledge relative and dynamic and reflected 
this epistemic belief in his SSI teaching in two ways. In the first of them, he shared the alternative scenarios related to the establishment of nuclear power plants with the class and attempted to make students understand the relative nature of the existing knowledge. In addition, in his question-answer-feedback exchanges with students, he attempted make students rediscover the shortcomings in their or others' statements, which seemed as if they were certain, by themselves through his counterarguments and suspicious questions.

With regard to whether (scientific) knowledge is simple or complex, the non-constructivist teacher, with her absolutist and static perspective, explained the technology-radiation relationship only by contextualizing the negative universals such as "technologies emit radiation" and "radiation is harmful to human health" on various examples such as mobile phones, x-ray devices, and nuclear power plants. Here, there is no knowledge or discussion about how technologies emit radiation, what kinds of damages the radiation has on human health, how this damage occurs if it has, and what kinds of differences there are between technologies in this process. Therefore, the knowledge was transferred in the form of rules, like reminding the rules to a spoiled student, mainly in an indoctrination manner, by asking the names of some technology types and by deduction from rule universals. On the other hand, it can be said that the evaluativist and dynamic perspective of the constructivist teacher was reflected in the process of constructing the knowledge to a certain extent. Indeed, this teacher attempted to make students understand an idea such as "there are several alternative ideas about whether nuclear power plants are harmful" and to make them compare and relate these alternative ideas with each other. In this dialogic process, various alternatives are constructed with their reasons and connected to each other with contrasts, inadequacies, and evaluations within a conceptual network. In fact, the fact that he described science as the interpretation of knowledge may have caused him to make such a conceptualization.

With respect to the justification of (scientific) knowledge, the absolutist and static epistemologies of the non-constructivist teacher might cause her to justify the knowledge only by herself and to transfer insufficient data like certain knowledge by completing them with her own emotions and intuitions in this justification process. Indeed, she also made a similar completion in the dinosaur scenario, which was used to reveal her knowledgebased epistemologies. Furthermore, it can be said that this teacher does not shape the difference between "informing" and "teaching" and preferred teaching only in the form of "informing." Indeed, she preferred information-oriented structures without justification components, such as "nuclear power emits radiation" and "cell phones cause cancer" that are mainly observed in the media, which are consistent with her recommending internet and encyclopedias as the resources for verifying the knowledge. When the constructivist teacher was examined, he reflected his evaluativist and dynamic epistemologies in his teaching and focused on "teaching" instead of "informing," unlike the non-constructivist teacher, which was manifested especially in his question-answer-evaluation exchanges with the students. He made students feel that they must absolutely justify their own claims (and produce the knowledge) by asking questions such as "why" and "what else" or by saying what the student says again and waiting. In addition, he reminded counterarguments instead of feedback such as "right" or "wrong," and in this way, he ensured that all possible alternatives would be argumented in the classroom environment. In another case, in the emotion/value-based arguments of the students, he reminded that knowledge should be based on solid evidence by reminding them emotion/value-based sections and offering them alternatives that could be evidence-based, and he emphasized the necessity of continuous testing of the validity and reliability processes. Indeed, in his utterances about the change of scientific theories and the relativity of knowledge, the fact that he constantly said 
that knowledge may change according to the conditions of the day and may lose its validity over time was coherent with this teaching orientation.

With regard to the source of (scientific) knowledge, the absolutist and static epistemologies of the non-constructivist teacher might cause her to see herself as an authority and to make emphasis as if everything she said was scientifically correct. The teacher even asked the questions and gave the answers by herself. In addition, the fact that she suggested nonindividual (non-student) sources such as encyclopedias and internet as the source of knowledge also confirms this situation. Furthermore, the fact that she thought that science was not affected by socio-cultural factors may have been influential in adopting a monologic teaching in which she was dominant. On the other hand, the evaluativist and dynamic epistemologies of the constructivist teacher might cause him to share his authority with students and cause them to become individuals who directed the discussion. His belief in the presence of uncertainties about the validity of knowledge might push him into the devil's advocate or a Socratic position rather than an authoritarian position, and he adopted the position of a "wise man" who thinks with the students and reminds them of coherences and evidence problems in their discourses.

Considering the above comparisons, while the moderately constructivist teacher was expected to have an epistemology-teaching coherence between the non-constructivist teacher and constructivist teacher, she developed a slightly stronger discourse than the SSI teaching of the non-constructivist teacher; however, her discourse was mostly monologic. Although this teacher mostly exhibited evaluativist and dynamic epistemologies, she did not allow for the discussion of alternative arguments in SSI teaching and attempted to direct her students to the knowledge structures in her mind through question-answerfeedback activities. In view of the certainty of (scientific) knowledge, although she considered knowledge as opinion, the fact that she focused on lack of evidence in the dinosaur scenario and her belief that the unknowns can be known with new studies over time in the example of atomic models showed that she believed that there may be a time-dependent uncertainty about knowledge, not a paradigmatic one. Indeed, although she presented two alternative scenarios related to nuclear power plants to the students in her SSI discourse, she directed the students towards the knowledge that he thought it was correct in her mind, and she probably found the evidence in that direction sufficient.

With regard to the simplicity of knowledge, it can be argued that the fact that she considered knowledge as a structure with complex relationships and connections was not reflected in her SSI discourse. Indeed, a weak construction of knowledge that ends with a knowledge structure regarding the fact that "nuclear energy emits radiation and harms people" was observed. In cases related to the justification and sources of knowledge, evaluativist and dynamic epistemologies were not reflected in SSI teaching discourse, that the discussion took place in an atmosphere where the teacher was dominant and directed the speech movements, and that students were not given opportunities to justify what they said or to refute opposing ideas. Although she considered (scientific) knowledge as an evidencebased structure, she did not perform a teaching that required finding evidences and thinking about these evidences, and that she only communicated more with students compared to the non-constructivist teacher. This situation was asked to her during the member check interview. Although she mostly had evaluativist and dynamic epistemologies, when she was told that she did not use them effectively in her teaching, she put forward her burnout as one of the reasons for it. She indicated that I do what the conditions require, instead of doing my best. At this point, she stated that there were many shortcomings in the education system in which she worked and that she felt unhappy because of them. She stressed that "the education system does not support teachers with regard to flexibility and creativity, I 
feel like I am atrophied." Furthermore, she stated that fifth-grade students were not suitable for discussion, already tended to accept what the teacher says and did not have enough knowledge to discuss. These reasons may have affected the fact that the teacher did not direct the students to a deeper and persistent discussion. In addition, when she was asked why she did not adequately discuss various alternatives related to nuclear power plants in the classroom, she stated that she was against nuclear power plants, that she was a member of some environmental protection organizations, and that nobody could convince her about her negative opinion. She stated that I am a member of Greenpeace and an environmental platform that is against nuclear power plants. I am against nuclear and I do not think my ideas will change. So, you cannot convince me. For instance, a nuclear power engineer could not convince me even though we had a long discussion. This situation indicates that some values arising from the nature of SSI conflict with epistemologies, that insufficient evidence can actually be compensated with values despite being aware of its inadequacy, and that this compensation can be quickly reflected in teaching. The negative motivational educational environment/atmosphere also seems to work as a facilitator in this completion process.

\section{Discussion}

In this study, three science teachers' epistemologies and SSI teaching were revealed and the coherence between them was examined. In accordance with the literature (Kilinc \& Baltaci, 2014; Kilinc et al., 2017a, b; Cano, 2005; Cheng et al., 2009; Chrysostomou \& Philippou, 2010; Hofer, 2000; Ozturk \& Yilmaz-Tuzun, 2017; Kizilgunes et al., 2009; Mateos et al., 2011; Phan, 2008; Phillips, 2001; Schommer, 1993), epistemologies were observed to be a parameter shaping the SSI teaching discourse. Science teachers are likely to develop knowledge-based and science-based beliefs about both general knowledge and the science they have studied, and these beliefs are also generally coherent with each other (Bryan, 2003; Buehl \& Alexander, 2001; Muis, 2004; Tsai, 2002). For instance, the teacher who develops evaluativist epistemologies on knowledge develops dynamic epistemologies on scientific knowledge, or, the teacher who develops absolutist epistemologies on knowledge develops static epistemologies on scientific knowledge. In addition, epistemologies diffuse into SSI teaching discourse through four main channels, including certainty, simplicity, justification, and sources of knowledge (Hofer, 2000).

Consistent with the findings of Kilinc and Baltaci (2014), Kilinc et al. (2017b) and Ozturk and Yilmaz-Tuzun (2017), the teacher with a more absolutist/static perspective regarding the certainty of knowledge attempted to impose the knowledge she accepted to the students as if it was a valid and reliable knowledge despite the insufficient evidence. This absolutist/static perspective might become a barrier for searching for counterarguments and constructing alternative arguments (Kilinc \& Baltaci, 2014; Ozturk \& YilmazTuzun, 2017). On the other hand, a teacher who is more evaluativist/dynamic regarding the simplicity of knowledge uses different pieces of arguments, has students make comparisons between them, and has them establish a conceptual network in this way. In addition, a teacher who has a more absolutist/static epistemology regarding the justification of knowledge complements insufficient evidence with her own values and emotions and presents it as if it was certain knowledge. She also seems to perform "informing" instead of "teaching." Indeed, while the information components independent of each other are directly transferred in the first one, question-answer-feedback relationships and 
justification procedures, which provide the meaning making and knowledge building processes, are established in the second one. On the other hand, consistent with the findings of Kilinc and Baltaci (2014), a teacher who is more evaluativist/dynamic regarding the source of knowledge shares his authority with the students and allows them to be individuals who direct the discussion. In addition, his belief in the presence of uncertainties about the validity of knowledge might push him into the devil's advocate or a Socratic position rather than an authoritarian position. When generally summarized, epistemological beliefs diffuse into SSI teaching with respect to the issues such as teachers' creating or searching alternatives in the knowledge, "teaching" or "informing" the knowledge, justification of knowledge with question-answer-feedback activities and speech moves, seeking evidence for knowledge or finding the justifications completed with emotions/values enough, establishing a conceptual network by making students associate and compare different pieces of knowledge, and sharing authority with the students.

In the second result, which complements the first result, either a monologic or a dialogic teaching was clearly observed in the SSI teaching of the non-constructivist and constructivist science teachers coherently with their epistemologies and constructivism profiles. However, although the SSI teaching discourse of the moderately constructivist teacher contained some developments, it was more like the discourse of the non-constructivist teacher. Although this teacher mostly had evaluativist/dynamic epistemologies, she stated that she preferred monologic teaching since the education system does not allow flexibility, she was against nuclear energy, and students had age-related deficiencies. Cheng et al. (2009) and Manu (2014) also showed a similar situation. Indeed, in both studies, the teachers with some constructivist elements did not reflect their evaluativist/dynamic epistemologies in the course and performed a monologic teaching due to the factors such as the pressure to complete the curriculum, workload, and test solving requirements. These results show that the transition from "absolutist/static epistemology_monologic teaching" to "evaluativist/ dynamic epistemology—dialogic teaching" cannot be provided only by an investment to develop epistemologies, and that in the intermediate forms the evaluativist/dynamic epistemologies may conflict with some infrastructural factors or values arising from the nature of SSI.

\section{Implications for Future Research}

The fact that science has shifted to a post-normal platform around the world (Ravetz, 2012) and the fact that SSI has been included in science curricula of many countries due to the demands of governments and science educators (Zeidler \& Kahn, 2014), however, many science teachers prefer monologic teaching instead of dialogic teaching (Kilinc et al., 2017a), which is essential for SSI teaching, were the starting points of this study. In this regard, it was focused on epistemologies as a factor that could be effective in shaping teachers' SSI teaching discourses (e.g., Ozturk \& Yilmaz-Tuzun, 2017), and this prediction was observed to be right. Indeed, when it was moved from more absolutist/static epistemologies to more evaluativist/dynamic epistemologies, it was observed that science teachers progressed from monologic SSI teaching to dialogic SSI teaching, which indicates that the development of epistemological beliefs and an explicit or implicit epistemology education are needed in the science teacher training. In the explicit version, a general "epistemology" course on the definitions of knowledge, knowledge-belief relations, certainty and relativity of knowledge, simplicity and complexity of knowledge, justification processes 
of knowledge, and sources of knowledge can be included in the science teacher training programs. Furthermore, how epistemologies diffuse into the scientific and socioscientific discourse through the mentioned four channels can be explained through the classroom practices (e.g., creating or searching for alternatives in the knowledge, question-answerfeedback activities and speech moves, sharing authority with students) exemplified in the present study. In the implicit version, it may be recommended for science teacher educators to prefer a more evaluativist/dynamic epistemic knowledge construction in all learning processes, depending on the branch on which the teacher learns (scientific) knowledge. It is anticipated that this version may be more effective than the first one since it is more longlasting and easier to internalize (Muis et al., 2006).

The investment only in epistemologies will not automatically result in a dialogic SSI teaching, as we clearly observed in the moderately constructivist teacher. Indeed, it is necessary to be sensitive to situations such as completing the curriculum and test question solving that are imposed by education systems, teachers' considerations that some activities in certain age groups cannot be performed, and the prevention of epistemologies by some values arising from the nature of SSI. It is considered that such situations will be shaped as desired with a long-term positive education. Indeed, when it is considered that the constructivist teacher is also in the same education system, the information to be obtained by examining how such teachers deal with system-based pressures, what positive beliefs they have about students' learning, and how they relate their values to their epistemologies can be shared with (pre-service) science teachers in the reflection-based discussion environments by taking them as a model, and possible barriers may be removed before they are formed. In addition, regarding the contradiction between personal values and the necessities of SSI teaching, the positions of "Democracy Advocator" and "Committed Impartialist" suggested by Kilinc et al. (2017b) can be introduced to (pre-service) science teachers so that they could efficiently manage their own values rather than imposing them or sticking only to facts without using them.

For future research, three lines of inquiriy can be pursued. First, the contradictions between epistemologies and values arising from the nature of SSI and how science teachers conduct exchanges between these two crucial mental resources during SSI classroom practices can be thoroughly investigated. Second, it seems that the social context of teaching and science teachers' beliefs about this context are influential in the development of undesired incoherence situations. Ethnographic works with longitudinal procedures may help us understand how such context-based factors determine which (epistemological, student-learning, and content-based) beliefs would be espoused and which beliefs would be enacted. Finally, we need intervention studies in order to clearly observe the co-development of beliefs (epistemologies and values) and teaching discourse practices. Testing different models of pre-service and in-service education may help us produce efficient coherence combinations.

Supplementary Information The online version contains supplementary material available at https://doi. org/10.1007/s11191-021-00200-7.

\section{Declarations}

Ethical Declaration The data collection tools in the present study were approved by a Turkish University Ethical Committee.

Conflict of Interest The authors declare that they have no conflict of interest. 


\section{References}

Akyıldız, S. (2014). Lise öğretmenlerinin epistemolojik inançları ile öğretme-öğrenme anlayışları arasındaki ilişkinin incelenmesi. [Investigating the relationship between high school teachers' epistemological beliefs and their teaching-learning approaches]. Unpublished doctoral dissertation, Firat University. Retrieved from http://tez2.yok.gov.tr/.

Appleton, K., \& Asoko, H. (1996). A case study of a teacher's progress toward using a constructivist view of learning to inform teaching in elementary science. Science Education, 80(2), 165-180.

Barrue, C., \& Albe, V. (2013). Citizenship education and socioscientific issues: Implicit concept of citizenship in the curriculum, views of French middle school teachers. Science \& Education, 22(5), 1089-1114.

Bryan, L. A. (2003). Nestedness of beliefs: Examining a prospective elementary teacher's belief system about science teaching and learning. Journal of Research in Science Teaching, 40(9), 835-868.

Bryan, L. A. (2012). Research on science teachers' beliefs. In B. J. Fraser, K. G. Tobin, \& C. J. McRobbie (Eds.), Second international handbook of science education. (pp. 477-495). Springer.

Buehl, M. M., \& Alexander, P. A. (2001). Beliefs about academic knowledge. Educational Psychology Review, 13(4), 385-418.

Cano, F. (2005). Epistemological beliefs and approaches to learning: Their change through secondary school and their influence on academic performance. British Journal of Educational Psychology, 75(2), 203-221.

Cazden, C. B. (2001). Classroom discourse: the language of teaching and learning. Heinemann.

Cheng, M. M., Chan, K. W., Tang, S. Y., \& Cheng, A. Y. (2009). Pre-service teacher education students' epistemological beliefs and their conceptions of teaching. Teaching and Teacher Education, 25(2), 319-327.

Chrysostomou, M., \& Philippou, G. N. (2010). Teachers' epistemological beliefs and efficacy beliefs about mathematics. Procedia-Social and Behavioral Sciences, 9, 1509-1515.

Eroğlu, B. (2012). Fen bilgisi öğretmen adaylarının küresel ısınma hakkındaki informal muhakemeleri üzerinde bilimin doğasının etkisinin araştırılması [A study about the nature of science?s effect on the preservice science teachers? informal reasoning about global warming]. Unpublished doctoral dissertation, Gazi University. Retrieved from http://tez2.yok.gov.tr/.

European Union. (2012). European Commissioner for research, innovation and science messages delivered at the conference "Science in Dialogue-Towards a European Model for Responsible Research and Innovation.", April 23-25, 2012.

Gayford, C. (2002). Controversial environmental issues: a case study for the professional development of science teachers. International Journal of Science Education, 24, 1191-1200.

Hashweh, M. Z. (1996). Effects of science teachers' epistemological beliefs in teaching. Journal of Research in Science Teaching, 33(1), 47-63.

Hofer, B. K. (2000). Dimensionality and disciplinary differences in personal epistemology. Contemporary Educational Psychology, 25, 378-405.

Hofer, B. K. (2002). Epistemological world views of teachers: from beliefs to practice. Issues in Education, $8(2), 167-173$.

Hofer, B. K. (2004). Exploring the dimensions of personal epistemology in differing classroom contexts: Student interpretations during the first year of college. Contemporary Educational Psychology, 29(2), 129-163.

Hofer, B. K., \& Pintrich, P. R. (2004). Personal epistemology: The psychology of beliefs about knowledge and knowing. Psychology Press.

Hofer, B. K., \& vePintrich, P. (1997). The development of epistemological theories: Beliefs about knowledge and knowing and their relation to learning. Review of Educational Research, 67, 88-140.

Hofer, B. K., ve Pintrich, P. R. (2002). Personal epistemology: the psychology of beliefs about knowledge and knowing. Lawrence Erlbaum Associates, Inc.

Johnston, P., Woodside-Jiron, H., \& Day, J. (2001). Teaching and learning literate epistemologies. Journal of Educational Psychology, 93(1), 223-233.

Kaplan, A. O., \& Akgul, E. M. (2009). Prospective elemantary science teachers' epistemological beliefs. Procedia-Social and Behavioral Sciences, 1(1), 2529-2533.

Kilinc, A., \& Baltaci, S. (2014). Preservice science teachers' epistemologies and efficacy regarding a socisocientific issue. 2014 NARST Annual Conference, March 30-April 2 2014, Pittsburgh, US.

Kilinc, A., Demiral, U., \& Kartal, T. (2017a). Resistance to dialogic discourse in SSI teaching: The effects of an argumentation-based workshop, teaching practicum, and induction on a preservice science teacher. Journal of Research in Science Teaching, 54(6), 764-789. 
Kilinc, A., Kelly, T., Eroglu, B., Demiral, U., Kartal, T., Sonmez, A., \& Demirbag, M. (2017b). Stickers to facts, imposers, democracy advocators, and committed impartialists: Preservice science teachers' beliefs about teacher's roles in socioscientific discourses. International Journal of Science and Mathematics Education, 15(2), 195-213.

Kizilgunes, B., Tekkaya, C., \& Sungur, S. (2009). Modeling the relations among students' epistemological beliefs, motivation, learning approach, and achievement. The Journal of educational research, 102(4), 243-256.

Kodish, S., \& Gittelsohn, J. (2011). Systematic data analysis in qualitative health research: Building credible and clear findings. Sight and Life, 25(2), 52-56.

Kuhn, D. (2001). How do people know? Psychological Science, 12, 1-8.

Kuhn, D., Iordanou, K., Pease, M., \& Wirkala, C. (2008). Beyond control of variables: What needs to develop to achieve skilled scientific thinking? Cognitive Development, 23, 435-451.

Kuhn, T. S. (1962). The structure of scientific revolutions. The Un. of Chicago Press, 2, 90.

Lazarowitz, R., \& Bloch, I. (2005). Awareness of societal issues among high school biology teachers teaching genetics. Journal of Science Education and Technology, 14(5-6), 437-457.

Lederman, N. G. (1992). Students' and teachers conceptions of the nature of science: a review of the research. Journal of Research in Science Teaching, 29, 331-359.

Lederman, N. G., Abd-El-Khalick, F., Bell, R. L., \& Schwartz, R. S. (2002). Views of nature of science questionnaire: Toward valid and meaningful assessment of learners' conceptions of nature of science. Journal of Research in Science Teaching, 39(6), 497-521.

Lee, H., Abd-El-Khalick, F., \& Choi, K. (2006). Korean science teachers' perceptions of the introduction of socio-scientific issues into the science curricuium. Canadian Journal of Science, 6(2), 97-117.

Lemke, J. L. (1990). Talking science: Language, learning, and values. Ablex Lessons.

Lincoln, Y. S., ve Guba, E. G. (1985). Naturalistic inquiry. Sage.

Manu, J. (2014). An investigation on relationship between epistemological beliefs and instructional practice of preservice and inservice teachers. Unpublished doctoral dissertation, University of North Dokata, USA. Retrived from https://commons.und.edu/theses/1683/.

Mateos, M., Cuevas, I., Martín, E., Martín, A., Echeita, G., \& Luna, M. (2011). Reading to write an argumentation: the role of epistemological, reading and writing beliefs. Journal of Research in Reading, 34(3), 281-297.

Ministry of National Education (MNE). (2013). Science education curricula (Grades 3-8). Retrieved from http://ttkb.meb.gov.tr/. Accessed on Mar 14, 2019.

Ministry of National Education (MNE). (2017). Science education curricula (Grades 3-8). Retrieved from http://ttkb.meb.gov.tr/ Accessed on Mar 14, 2019.

Ministry of National Education (MNE). (2019). Science education curricula (Grades 3-8). Retrieved from http://ttkb.meb.gov.tr/ Accessed on Mar 14, 2019.

Muis, K. R. (2004). Personal epistemology and mathematics: a critical review and synthesis of research. Review of Educational Research, 74, 317-377.

Muis, K. R., Bendixen, L. D., \& Haerle, F. C. (2006). Domain-generality and domain-specificity in personal epistemology research: Philosophical and empirical reflections in the development of a theoretical framework. Educational Psychology Review, 18(1), 3-54.

Ozturk, N., \& Yilmaz-Tuzun, O. (2017). Preservice science teachers' epistemological beliefs and informal reasoning regarding socioscientific issues. Research in Science Education, 47(6), 1275-1304.

Phan, H. P. (2008). Predicting change in epistemological beliefs, reflective thinking and learning styles: a longitudinal study. British Journal of Educational Psychology, 78(1), 75-93.

Phillips, F. (2001). A research note on accounting students' epistemological beliefs, study strategies, and unstructured problem-solving performance. Issues in Accounting Education, 16(1), 21-39.

Ratcliffe, M., \& Grace, M. (2003). Science education for citizenship: Teaching socio-scientific issues. McGraw-Hill Education.

Ravetz, J. (2012). The significance of the Hamburg workshop: Post-normal science and the maturing of science. Nature and Culture, 7(2), 133-150.

Reznitskaya, A. (2012). Dialogic teaching: Rethinking language use during literature discussions. The Reading Teacher, 65(7), 446-456.

Ross, S. M., Smith, L. J., Alberg, M., \& Lowther, D. (2004). Using classroom observation as a research and formative evaluation tool in educational reform. Observational research in US classrooms: New approaches for understanding cultural and linguistic diversity, 144-173.

Schommer, M. (1990). Effects of beliefs about the nature of knowledge on comprehension. Journal of Educational Psychology, 82, 498-504.

Schommer, M. (1994). Synthesizing epistemological belief of research: Tentative understandings and provocative confusions. Educational Psychology Review, 6(4), 293-319. 
Schommer, M. A. (1993). Epistemological development and academic performance among secondary schools. Journal of Educational Psychology, 85(3), 406-411.

Songer, N. B., \& Linn, M. C. (1991). How do students' views of science influence knowledge integration? Journal of Research in Science Teaching, 28(9), 761-784.

Tsai, C. C. (2000). Relationships between student scientific epistemological beliefs and perceptions of constructivist learning environments. Educational Research, 42(2), 193-205.

Tsai, C. C. (2002). Nested epistemologies: Science teachers' beliefs of teaching, learning and science. International Journal of Science Education, 24(8), 771-783.

Tsai, C. C. (2007). Teachers' scientific epistemological views: the coherence with instruction and students' views. Science Education, 91(2), 222-243.

Zeidler, D. L., \& Kahn, S. (2014). It's debatable!: Using socioscientific issues to develop scientific literacy $K$-12. NSTA press.

Zeidler, D. L., \& Nichols, B. H. (2009). Socioscientific issues: Theory and practice. Journal of Elementary Science Education, 21(2), 49-58.

Publisher's Note Springer Nature remains neutral with regard to jurisdictional claims in published maps and institutional affiliations. 